\title{
Zambia: Los educadores juveniles pueden promover comportamientos sexuales más seguros
}

Frontiers in Reproductive Health

Follow this and additional works at: https://knowledgecommons.popcouncil.org/departments_sbsr-rh

Part of the Civic and Community Engagement Commons, Demography, Population, and Ecology Commons, International Public Health Commons, and the Public Health Education and Promotion Commons How does access to this work benefit you? Let us know!

\section{Recommended Citation}

"Zambia: Los educadores juveniles pueden promover comportamientos sexuales más seguros," FRONTERAS Resúmenes de Investigación Operativa. Ciudad de México: Population Council, 2001. 


\section{Los educadores juveniles pueden}

Salud reproductiva de adolescentes

\section{Resumen de IO 12 Dos intervenciones, la distribución de condones por parte de educadores juveniles y los pequeños préstamos comerciales a jóvenes de 14 a 19 años de edad, produjeron prácticas sexuales más seguras entre los adolescentes de comunidades periurbanas. Tanto los participantes del programa como sus compañeros informaron un aumento de abstinencia y monogamia y una reducción de infecciones de transmisión sexual. Los adolescentes de las áreas de intervención estaban mejor informados sobre cómo prevenir el VIH/SIDA que los del grupo de control. Sin embargo, las intervenciones no aumentaron el uso de anticoncepción o condones para una protección dual.}

\section{Antecedentes}

Durante 1996-1998, CARE Zambia, con apoyo del Population Council, realizó un estudio para probar estrategias comunitarias para mejorar la salud sexual y reproductiva de los adolescentes. Con la colaboración de la Asociación de Paternidad Responsable de Zambia y del Centro Ecuménico Makeni, CARE Zambia habló con los adolescentes de cuatro comunidades ubicadas fuera de Lusaka. Los investigadores identificaron, mediante técnicas de aprendizaje y acción participativos (AAP), un gran número de factores que producen comportamientos sexuales de alto riesgo, entre ellos la falta de oportunidades económicas, recreativas y educativas para la juventud.

Esta información ayudó a diseñar este estudio, el cual se llevó a cabo durante 20 meses en cuatro áreas: (1) distribución de condones por educadores juveniles; (2) préstamos a adolescentes de 14-19 años de edad para iniciar negocios pequeños, capacitándolos en habilidades comerciales y dándoles información sobre salud sexual y reproductiva (SSR); (3) una tercer área, en la que se implementaron ambas intervenciones y (4) una cuarta área que sirvió de control.

Se recolectaron datos antes y después de la intervención en las cuatro comunidades del estudio.
La información se obtuvo con técnicas de AAP, entrevistas a profundidad con 35 educadores juveniles y 47 beneficiarios de préstamos, encuestas a 83 educadores juveniles y 103 beneficiarios de préstamos, una encuesta basal a 1,634 adolescentes y una encuesta post-intervención a 1,720 adolescentes.

\section{Resultados}

Los 130 adolescentes capacitados para ser educadores juveniles realizaron más de 4,000 sesiones de consejería de SSR y distribuyeron más de 65,600 condones, lo que significó alcanzar del 4 al 15 por ciento de los adolescentes de sus áreas. Sin embargo, la mayoría de los jóvenes que utiliza condones los obtiene en el mercado o en tiendas.

Los jóvenes que recibieron préstamos aprendieron nuevas habilidades y cambiaron su perspectiva del futuro. De los 221 adolescentes que recibieron préstamos de US \$67 en promedio, la mitad fueron mujeres y ninguna de ellas asistía a la escuela. Casi cuatro de cada cinco de los 47 beneficiarios de préstamos entrevistados dijeron que habían logrado hacer algo "útil" con ese dinero, como satisfacer necesidades familiares y personales, inscribirse en una escuela y comprar mercancías para su negocio, entre otras cosas. 
Sin embargo, la intervención no produjo un sistema de crédito revolvente, ya que menos de la tercera parte de los préstamos fue reembolsada. Esto se debió a que algunos jóvenes tuvieron que pagar deudas familiares, se enfermaron o prestaron dinero que no les fue devuelto. Las mujeres fueron más responsables que los hombres para pagar sus créditos.

La intervención de los educadores juveniles tuvo mayor efecto en el comportamiento sexual de los participantes que la del esquema de préstamos. Casi todos los 83 educadores juveniles y cerca de la mitad de los 103 jóvenes beneficiarios de préstamos que respondieron a la encuesta realizada al final del proyecto, informaron que aumentó la abstinencia y la monogamia en los últimos tres meses del estudio y que sabían más sobre cómo prevenir el VIH/SIDA.

Ambas intervenciones produjeron comportamientos sexuales más seguros dentro de la comunidad. Se observaron los siguientes cambios en las tres áreas de intervención, pero no en la de control: más adolescentes informaron ser monógamos en los últimos tres meses (véase la gráfica), más jóvenes pudieron nombrar por lo menos dos formas de evitar el contagio del VIH/SIDA, menos jóvenes habían padecido una ITS en los últimos nueve meses y más adolescentes solicitaron tratamiento para ITS en una clínica. No se encontraron diferencias en cuanto al uso del condón o de anticonceptivos en los últimos tres meses, ni en la edad o proporción de adolescentes que iniciaron su vida sexual. Al combinar las dos intervenciones no se obtuvo un impacto mayor.

\section{Implicaciones normativas}

A los adolescentes les preocupa la salud reproductiva, así como contar con oportunidades de trabajo y de educación, por lo que necesitan programas integrales que aborden sus distintas necesidades.

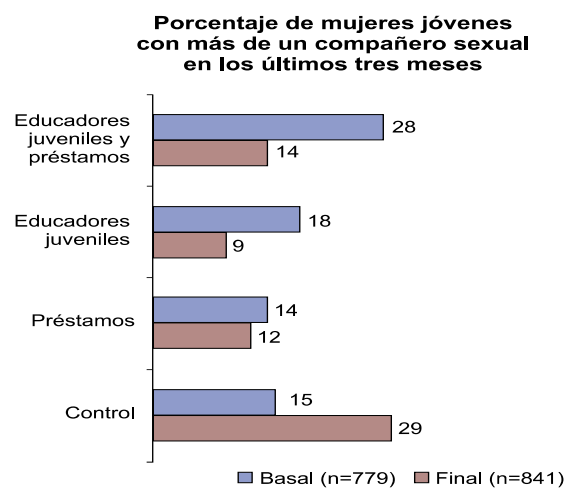

Los programas de educadores juveniles implican mucho trabajo, pero pueden producir comportamientos sexuales más seguros tanto entre los educadores como entre los jóvenes a quienes asesoran.

Los programas de préstamos benefician a los jóvenes que no asisten a la escuela, pero son difíciles de mantener por los problemas de reembolso de los mismos. Al seleccionar a los beneficiarios de un préstamo, se debería escoger a mujeres jóvenes, a adolescentes que ya tengan un negocio y a los que estén dispuestos a abrir una cuenta de ahorros. Se recomienda que el periodo de gracia y la fecha límite del reembolso sean cortos para motivar la devolución del préstamo.

Es necesario que los programas reduzcan el estigma que los jóvenes asocian al uso del condón.

Mayo 2001

Fetters, Tamara, Fines Munkonze, y Julie Solo. 1999. Investing in Youth: Testing Community Based Approaches for Improving Adolescent Sexual and Reproductive Health. CARE Zambia y el Population Council. Para obtener más información escriba o llame a: Population Council, P.O. Box 17643, Nairobi, Kenia. Tel. 254-2-713-480; Fax 254-2-713-479; E-mail: publications@ popcouncil.or.ke.

Este proyecto se llevó a cabo con el apoyo de la Agencia de los Estados Unidos para el Desarrollo Internacional (USAID), de conformidad con el Contrato número CCP-3030-C-00-3008-00. 